\title{
In Vitro Biological Screening of Hartmannia rosea Extracts
}

\author{
Rehana Rashid, ${ }^{1}$ Abida Kalsoom Khan, ${ }^{1}$ Ihsan Ul Haq, ${ }^{2}$ Sadullah Mir, ${ }^{1}$ Sadaf Mehmood, \\ Yi Lu, ${ }^{3}$ and Ghulam Murtaza ${ }^{4}$ \\ ${ }^{1}$ Department of Chemistry, COMSATS Institute of Information Technology, Abbottabad 22060, Pakistan \\ ${ }^{2}$ Department of Pharmacy, Quaid-i-Azam University, Islamabad 45320, Pakistan \\ ${ }^{3}$ School of Preclinical Medicine, Beijing University of Chinese Medicine, Beijing 100029, China \\ ${ }^{4}$ Department of Pharmacy, COMSATS Institute of Information Technology, Abbottabad 22060, Pakistan
}

Correspondence should be addressed to Rehana Rashid; rehanar@ciit.net.pk and Yi Lu; yilubucm@gmail.com

Received 14 June 2017; Revised 23 August 2017; Accepted 6 September 2017; Published 4 December 2017

Academic Editor: Wan-Liang Lu

Copyright (C) 2017 Rehana Rashid et al. This is an open access article distributed under the Creative Commons Attribution License, which permits unrestricted use, distribution, and reproduction in any medium, provided the original work is properly cited.

The present study is focused on the assessment of the medicinal therapeutic potential extracts of $H$. rosea to investigate their pharmacological implications based upon science proofs. The antioxidant activity of fraction of $H$. rosea, namely, $n$-hexane (HR-1), ethyl acetate (HR-2), chloroform (HR-3), and $n$-butanol (HR-4), was performed by using the DPPH radical scavenging method. The cytotoxicity and enzyme inhibition assessment were also performed. All the extracts showed significant antioxidant, antibacterial, and protein kinase inhibition but none of the extracts exhibited $\alpha$-amylase inhibition activity. The chloroform extract HR-3 may block a kinase receptor from binding to ATP; the lead molecule will be isolated, which may stop cancerous cell growth and demotion of cell division. It is predicted that ethyl acetate, chloroform, and $n$-butanol extracts of $H$. rosea contain polyphenolics, flavonoids, and alkaloids that are biologically effective candidates exhibiting significant cytotoxicity, antioxidant, and antimicrobial activities. They may control oxidative damage in the body tissues and act as potential antidiabetic and anticancer agents. These studies will also be helpful for future drug designing and drug development research.

\section{Introduction}

Natural products have been used for centuries for the treatment of ailments, mostly in developing countries, where the economic resources are limited and affordability and access to modern treatment is scarce [1]. Hartmannia also known as Oenothera is a large and medicinally important genus of plants with approximately 124 species belonging to the Onagraceae family. Hartmannia rosea (H. rosea) plant species is commonly known as evening primrose, found in USA and Mexico and also widely grown in localities like Hazara, Poonch, Kashmir, and Jhelum valley in Pakistan [2].

Since herbal medicine can be used as an alternative medicine due to its cost effectiveness and lesser side effects, extensive research has been carried out to update the ethnomedicinal plant remedies through standardization and quality control for their recognition and acceptance in the international community. Numerous compounds have been isolated from genus Hartmannia, yet there are some therapeutically imperative species for which insufficient work is accounted.

Oil from seeds of evening primrose is a rich source of $\gamma$-linoleic acid, used for the production of prostaglandins and related hormones [3]. Its oral dosages have been used to treat breast disorders, atopic eczema, premenstrual tension, and rheumatoid arthritis [4]. Previously, antioxidant [5], antitumor [6], antimicrobial [7], anti-inflammatory [8], antidiarrhoeic [9], and antisecretary [10] activities of its different species have been reported.

The aqueous extracts of Hartmannia rosea have been used as folk medicine for headache, inflammation, cough, diarrhea, scabies, staphylococcal infection, pimples, stomatitis, liverwort, and hepatic and kidney diseases [11]. The antidiarrheal potential of decoction of $H$. rosea has been reported in the diarrhoeic mice stimulated with castor oil [9]. The aqueous and methanolic extracts of $H$. rosea showed 
significant inhibitory effect against inflammation, through the in vivo study done on adult female Wistar rats and male $\mathrm{NIH}$ mice. It has been demonstrated that these extracts did not show any perniciousness and induced significant antiinflammatory activity [8]. The methanolic extract of aerial parts has also been used for the treatment of bruises and swelling [12]. The ethanol, acetone, and ethyl acetate fractions of $H$. rosea show antioxidative efficacy [13]. The $90 \%$ ethanolic and aqueous extracts of stem and roots of $H$. rosea exhibited anthelmintic potential [14]. The percentage inhibition of heart contractile activity of male Wistar rats was evaluated at the dose of $1.0 \mathrm{mg} / \mathrm{mL}$ [15]. The literature review interpreted that very limited research work has been accomplished on $H$. rosea, whereas most of the pharmacological potentials of this beneficial plant species are unexplored. In the present investigation antioxidant, antimicrobial, protein kinase inhibitor, $\alpha$ amylase, and cytotoxic efficacies of different solvent extracts of $H$. rosea are reported for the first time using different protocol and strains.

\section{Materials and Methods}

2.1. Preparation of the Hartmannia rosea Extracts. The plant species Hartmannia rosea (Onagraceae) was collected from Abbottabad during its flowering season from April to June 2013. Methanol, $n$-hexane, ethyl acetate, chloroform, and $n$ butanol of commercial grade were purchased locally (Shalimar Chemicals, Rawalpindi, Pakistan).

The whole plant $H$. rosea was dried under shade and it was ground into powder. $5 \mathrm{~kg}$ of the powdered material was soaked in $10 \mathrm{~L}$ methanol for fortnight. The methanolic extract was filtered and dark greenish brown filtrate was evaporated on vacuum rotary evaporator (Heidolph-HeiVAP Germany) to obtain crude extract, and this process was repeated thrice. The methanolic extract was fractionated on the basis of solvent polarity like $n$-hexane (HR-1), ethyl acetate (HR-2), chloroform (HR-3), and n-butanol (HR-4). The dried extracts were used for the estimation of subsequent biological activities.

2.2. Biological Assessments. Extracts of $H$. rosea (HR) were used for the determination of total antioxidant capacity (TAC), total reducing power (TRP) and free radical scavenging activity (RSA) by DPPH assay.

2.2.1. Radical Scavenging Activity (DPPH Assay). The antioxidant efficacy of four extracts of $H$. rosea was determined by assessing their capacity of quenching the stable 2,2diphenyl-1-picrylhydrazyl (DPPH) free radical scavenging activity (RSA, \%) by using UV spectroscopic analysis [16, 17]. The $\mathrm{IC}_{50}$ is the concentration at which it inhibits $50 \%$ free radical formation. $180 \mu \mathrm{L}$ of $(9.2 \mathrm{mg} / 100 \mathrm{~mL}$ methanol $)$ 2,2-diphenyl-1-picrylhydrazyl (DPPH) reagent was added to 96 -well plates, already containing $20 \mu \mathrm{L}$ of each extract (HR-1, HR-2, HR-3, and HR-4), respectively, and each of the wells contained $200 \mu \mathrm{L}$ as final volume. Ascorbic acid and reagent were used as positive and negative controls, respectively. Then the sample well plates were incubated for 1 hour at $37^{\circ} \mathrm{C}$ and absorbance was taken at $517 \mathrm{~nm}$ by using microplate reader (Biotek-ELx800 Absorbance Reader made by Wolflabs). Experiment was performed in triplicate on each sample and radical scavenging activity (\%) was calculated by using the formula

$$
\text { Inhibition percentage }=A c-\frac{A s}{A c} \times 100 .
$$

As is the absorbance of the sample with reagent DPPH, while Ac is the absorbance of the control without sample. The ascorbic acid was used as standard positive control.

2.2.2. Total Antioxidant Capacity (TAC). Phosphomolybdenum method was used for the measurement of total antioxidant capacity of the extracts [18]. The extracts HR-1, HR-2, HR-3, and HR- 4 were tested by mixing $0.1 \mathrm{~mL}$ of each extract ( $4 \mathrm{mg} / \mathrm{mL}$ DMSO) with $1 \mathrm{~mL}$ reagent $(4 \mathrm{mM}$ ammonium molybdate, $28 \mathrm{mM}$ sodium phosphate, and $0.6 \mathrm{M}$ sulphuric acid), ascorbic acid $(4 \mathrm{mg} / \mathrm{mL})$ as positive control and $1 \mathrm{~mL}$ reagent as blank were incubated for $90 \mathrm{~min}$ at $95^{\circ} \mathrm{C}$. The samples were cooled down to room temperature and absorbance of each reaction mixture was measured at $695 \mathrm{~nm}$ (Biotek-EL x 800 Absorbance Reader made by Wolflabs). The experiment was performed in triplicate. The antioxidant capacity was expressed as the number of mg equivalent of ascorbic acid per mg of the sample. Calibration curve was prepared by taking the concentration of ascorbic acid as $125 \mu \mathrm{g} / \mathrm{mL}, 100 \mu \mathrm{g} / \mathrm{mL}$, $75 \mu \mathrm{g} / \mathrm{mL}, 50 \mu \mathrm{g} / \mathrm{mL}$, and $25 \mu \mathrm{g} / \mathrm{mL}$.

\subsubsection{Total Reducing Power (TRP) Estimation by Colorimetric} Assay. The reducing power of four extracts was estimated by the predescribed method [19]. $100 \mu \mathrm{L}$ of each fraction, that is, HR-1, HR-2, HR-3, and HR-4 (4 mg/mL DMSO), was mixed with $400 \mu \mathrm{L}$ of $0.2 \mathrm{~mol} / \mathrm{L}$ phosphate buffer of $\mathrm{pH} 6.6$ and $500 \mu \mathrm{L}$ of $1 \%$ potassium ferricyanide $\left[\mathrm{K}_{3} \mathrm{Fe}(\mathrm{CN})_{6}\right]$. The reaction mixture was then incubated at $50^{\circ} \mathrm{C}$ for $20 \mathrm{~min}$ and after incubation $500 \mu \mathrm{L}$ of $10 \%$ trichloroacetic acid was added to it. Mixture was centrifuged at $3000 \mathrm{rpm}$ for $10 \mathrm{~min}$ at room temperature. The $100 \mu \mathrm{L}$ supernatant solution was poured in 96-well plates, respectively, and $20 \mu \mathrm{L}$ distilled water was added along with $100 \mu \mathrm{L}$ ferric chloride (0.1\%). DMSO with previously prescribed reaction mixture was used as blank without sample. The absorbance was measured at $630 \mathrm{~nm}$ on microplate reader. The reducing power was expressed as $\mathrm{mg}$ ascorbic acid equivalent per gram extracts.

\subsubsection{Cytotoxicity Measurement}

(1) Brine Shrimp Lethality Assay. The cytotoxic efficiency of $H$. rosea extracts was tested in a 96-well plate against brine shrimp (Artemia salina) nauplii (Ocean 90, USA) for their lethality test as per known protocol [20]. The cytotoxicity screening of the extracts of $H$. rosea was performed by dissolving $n$-hexane (HR-1), ethyl acetate (HR-2), chloroform (HR-3), and butanol (HR-4) extracts in DMSO. The nauplii were transferred to each well plate and the test extracts were applied against Artemia salina for 24 hours at room temperature. The positive control doxorubicin $(4 \mathrm{mg} / \mathrm{mL})$ and negative controls DMSO were treated in similar manner. They were incubated at room temperature for $24 \mathrm{~h}$. After 
incubation period the degree of lethality exhibited by each extract was determined through counting the number of survivors under 3x magnifying glass against illuminated background, and median lethal dose $\left(\mathrm{LD}_{50}\right)$ of the extract fractions with $>50 \%$ mortality was observed. The experiment was performed in triplicate.

\subsection{Antimicrobial Activity Test}

2.3.1. Antifungal and Antibacterial Activity. Different microbes were used for testing the antimicrobial activity of $H$. rosea extracts. The following two types of assays were performed in order to determine the antimicrobial activity of four extracts. Two bacterial strains, such as Pseudomonas aeruginosa (P. aeruginosa) (Gram-negative) and Staphylococcus aureus (S. aureus) (Gram-positive), were used for the antibacterial activity. Antifungal activity was performed against Aspergillus niger (FCBP-0198), Aspergillus fumigatus (FCBP066), and Mucor species (FCBP-0300).

DMSO, nutrient agar, reference antibiotic (CefotaximeUSP) and Sabouraud dextrose agar (SDA, Merck, Germany) medium was used for antifungal assay. Dimethyl sulfoxide (DMSO) was used for the dilutions of the samples.

Agar Disc Diffusion Method. Agar disc diffusion method was used to check the antibacterial activity of fractions of $H$. rosea [21]. Media were prepared by dissolving $23 \mathrm{~g}$ of nutrient agar in $1 \mathrm{~L}$ of distilled water adjusting the $\mathrm{pH}$ of the media as 7 and autoclaved at $121^{\circ} \mathrm{C}$ for $20 \mathrm{~min} .25 \mathrm{~mL}$ of agar medium was poured in already sterilized Petri dishes and allowed to solidify. The already prepared inoculums of each bacterium were swabbed smoothly on the surface of the media of each plate and labeled. The sterile filter paper discs of $6 \mathrm{~mm}$ size were impregnated with $2.5 \mu \mathrm{L}$ of fractions in DMSO by means of micropipette and kept for drying in laminar flow. The solution $(1 \mathrm{mg} / \mathrm{mL}$ in DMSO) of standard antibiotic cefotaxime-USP was used as positive control and negative control blank discs were made with DMSO solvent. The test sample discs and standard and blank discs were overlaid on the surface of the agar Petri dishes. The discs were incubated at $37^{\circ} \mathrm{C}$ for about 24 hours. After incubation the zones of inhibition (ZOI) were measured in $\mathrm{mm}$ as the difference between the diameter of disc and the diameter of inhibition. The same procedure was repeated in triplicate for each sample.

Minimum inhibitory concentration (MIC) was considered as the minimal concentration of the sample fractions that inhibited the bacterial growth, after $24 \mathrm{~h}$ incubation at $37^{\circ} \mathrm{C}$. Antifungal efficacy of the $H$. rosea fractions was estimated as triplicate analysis using the disc diffusion method [21]. Three fungal strains, namely, Aspergillus niger (FCBP0198), Aspergillus fumigatus (FCBP-066), and Mucor species (FCBP-0300), were grown by using Sabouraud dextrose agar (SDA) containing $62 \mathrm{~g} / \mathrm{L}$ of SDA dissolved in distilled water. The four fractions of $H$. rosea, namely, HR-1, HR-2, HR3 , and HR-4, were dissolved separately in DMSO, so that the concentration of each fraction was $20 \mathrm{mg} / \mathrm{mL}$ of DMSO. Then, sterile filter paper discs were impregnated with $5 \mu \mathrm{L}$ of each of the sample fractions. DMSO treated disc was used as negative and $20 \mu \mathrm{g} /$ disc clotrimazole $(4 \mathrm{mg} / \mathrm{mL})$ standard drug as positive control. The plates were incubated at $28^{\circ} \mathrm{C}$ for $24 \mathrm{~h}$.

\subsection{Inhibitory Properties against Enzymes}

2.4.1. Suppression of Protein Kinase. The protein kinase suppression was conducted by observing generation of hyphae (HFI) in purified isolates of Streptomyces 85E strain [22]. Mycelia fragments of Streptomyces were spread on sterile agar plates containing mineral ISP4 medium for the development of bacterial lawn. The sterile $6 \mathrm{~mm}$ filter paper discs were impregnated with $5 \mu \mathrm{L}$ of each fraction $(20 \mathrm{mg} / \mathrm{mL}$ of DMSO) and they with final concentration of $100 \mu \mathrm{g} /$ disc were applied on the surface of Streptomyces 85E seeded agar plates. Surfactin standard (80-0.02\% in distilled water) and DMSO infused discs were also included as positive and negative controls, respectively. All the plates with sample loaded and controls were incubated at $30^{\circ} \mathrm{C}$ for $72-96 \mathrm{~h}$. The bald zones of inhibition around controls infused discs and samples were evaluated.

2.4.2. Alpha-Amylase Inhibition Assessment. Alpha-amylase inhibition assay was performed using a modified protocol [23]. The enzyme inhibition kept the undigested starch that was determined at $630 \mathrm{~nm}$ (blue complex of StarchIodine). Phosphate buffer solution (PBS) pH 6.8 was prepared. $0.5 \mathrm{mg} \alpha$-amylase (28 U/mg) containing $14.37 \mathrm{U}$ was dissolved in $1 \mathrm{~mL}$ of phosphate buffer solution. It was then diluted to $0.12 \mathrm{U} / \mathrm{mL}$. The stock solutions of each extract ( $4 \mathrm{mg} / \mathrm{mL}$ ), starch $2 \mathrm{~g} / \mathrm{L}$, iodine reagent (containing $5 \mathrm{mM} \mathrm{I}_{2}$ and $5 \mathrm{mM}$ potassium iodide), positive control, and acarbose $(8.64 \mathrm{mg} / \mathrm{mL})$ were prepared in DMSO. The reaction mixture contained $15 \mu \mathrm{l}$ phosphate buffer (pH 6.8), $25 \mu \mathrm{l} \alpha$-amylase enzyme, $40 \mu \mathrm{l}$ starch, and $10 \mu \mathrm{l}$ extract $(100 \mu \mathrm{g} / \mathrm{mL}$ final concentration) which were incubated for $30 \mathrm{~min}$ at $50^{\circ} \mathrm{C}$. The reaction was terminated by adding $20 \mu \mathrm{l} \mathrm{HCl}(1 \mathrm{M})$ into the reaction mixture. Then, $90 \mu$ l iodine reagent was added to each well. This resulted in the change of color in those wells where starch was left due to inhibition of enzyme, and absorbance was measured at $360 \mathrm{~nm}$. A blank (buffer, starch, enzyme, and DMSO), a negative control DMSO, and a positive control acarbose were used for the comparison of results. Intense blue color indicated the strong activity. The assay was performed in triplicate in 96-well microtiter plate reader. Results were expressed as percentage $\alpha$-amylase inhibition.

$$
\text { Inhibition }(\%)=\frac{\left(\mathrm{Ac}^{+}\right)-\left(\mathrm{Ac}^{-}\right)-(\mathrm{As}-\mathrm{Ab})}{\left(\mathrm{Ac}^{+}\right)-\left(\mathrm{Ac}^{-}\right)} \times 100 \text {, }
$$

where $\mathrm{Ac}^{+}$and $\mathrm{Ac}^{-}$represent positive and negative control, respectively, while As is used for sample and $\mathrm{Ab}$ for blank. $50 \%$ inhibition of sample and acarbose is the $\mathrm{IC}_{50}$ value.

2.5. Statistical Analysis. The results obtained for cytotoxicity and antimicrobial assays were expressed as mean \pm standard error of mean (SEM). Comparisons were performed within groups by the analysis of variance using the ANOVA test. Significant differences between control and experimental groups were assessed by the Sigma Stat software. A probability level $P<0.05$ was considered to indicate statistical significance. 
TABLE 1: $\mathrm{IC}_{50}$ values for DPPH radical scavenging activity of Hartmannia rosea extracts. Values are presented as the mean \pm SEM of experiments performed in triplicate.

\begin{tabular}{lcc}
\hline Plant extract & $\mathrm{IC}_{50}$ Value & RSD (\%) \\
\hline$n$-Hexane (HR-1) & $15.30 \pm 0.20^{*}$ & 1.315 \\
Ethyl acetate (HR-2) & $7.37 \pm 0.26^{*}$ & 3.575 \\
Chloroform (HR-3) & $11.40 \pm 0.30^{*}$ & 2.631 \\
$n$-Butanol (HR-4) & $7.60 \pm 0.26^{*}$ & 3.481 \\
Ascorbic acid (As) & 25.38 & 91.75 \\
\hline
\end{tabular}

Note. * indicates significant results $(P<0.05)$.

\section{Results}

The extraction efficacy is not dependent only upon the change in the composition of extractable plant metabolites and the polarity of the solvents used but their biological activities are also influenced as the diversity in the nature of components has specific solubility. Hence multiple extracts of crude methanolic extract of $H$. rosea were employed for the biological evaluation.

\subsection{Biological Assessment}

3.1.1. DPPH Radical Scavenging Activity of $H$. rosea Extracts (RSA, \%). The results of percent free radical scavenging activity of different extracts of $H$. rosea demonstrated that ethyl acetate (HR-2) extract ( $\left.\mathrm{IC}_{50} 7.37 \mu \mathrm{g} / \mathrm{mL}\right)$ and $n$-butanol extracts (HR-4) ( $\left.\mathrm{IC}_{50} 7.60 \mu \mathrm{g} / \mathrm{mL}\right)$ showed highest antioxidant activity, while chloroform extract (HR-3) with $\mathrm{IC}_{50}$ 11.40 and $n$-hexane (HR-1) have the lowest $\left(\mathrm{IC}_{50} 15.30 \mu \mathrm{g} / \mathrm{mL}\right)$ activity equivalent to standard ascorbic acid at $50 \mu \mathrm{g} / \mathrm{mL}=$ 91.75\% and $\mathrm{IC}_{50} 25.38 \mu \mathrm{g} / \mathrm{mL}$ (Table 1).

3.1.2. Total Antioxidant Capacity. Total antioxidant capacity (TAC) of various extracts of $H$. rosea is studied. The Mo(VI) has been reduced by the antioxidant extract to $\mathrm{Mo}(\mathrm{V})$ and the absorption of resultant phosphate/ $\mathrm{Mo}(\mathrm{V})$ complex of green color was measured at $695 \mathrm{~nm}$ [24].

The ethyl acetate fraction (HR-2) and $n$-butanol extract (HR-4) showed more significant results at the ascorbic acid equivalent $\mu \mathrm{g} / \mathrm{mg}$ sample of 419.71 and 328.13, respectively, while other extracts were less effective (Figure 1).

3.1.3. Total Reducing Power (TRP). The reducing power of $n$ hexane (HR-1), ethyl acetate (HR-2), chloroform (HR-3), and $n$-butanol (HR-4) extracts ( $100 \mu \mathrm{L}$ concentration) is exhibited (Figure 2). Hence ethyl acetate (HR-2) $698.7 \mu \mathrm{g} / \mathrm{mg}$ and $n$ butanol extract (HR-4) $692 \mu \mathrm{g} / \mathrm{mg}$ were found more active than other extracts, since the extracts having the reducing power in fact have the power of electron donation and are capable of reducing the oxidized intermediates formed in lipid peroxidation phenomena [25].

3.2. Cytotoxicity of H. rosea Extracts. The brine shrimp lethality assay is suitable and simple too for primary assessment of toxicity. The median lethal dose of the toxicity $\left(\mathrm{LD}_{50}\right)$ for the $H$. rosea extracts HR-1, HR-2, HR-3, and HR-4 is presented in Table 2 . The extracts of $H$. rosea were screened for cytotoxic

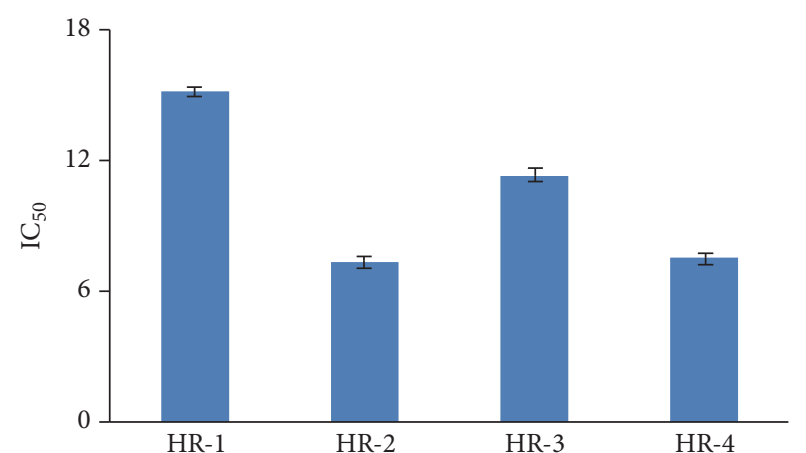

FIgURE 1: Total antioxidant capacity (TAC) $\mathrm{mg} / \mathrm{mL}$ in different solvent extracts of $H$. rosea. Values are presented as mean \pm standard error from triplicate experiment. HR-1: $n$-hexane, HR-2 ethyl acetate, HR-3: chloroform, and HR-4: $n$-butanol.

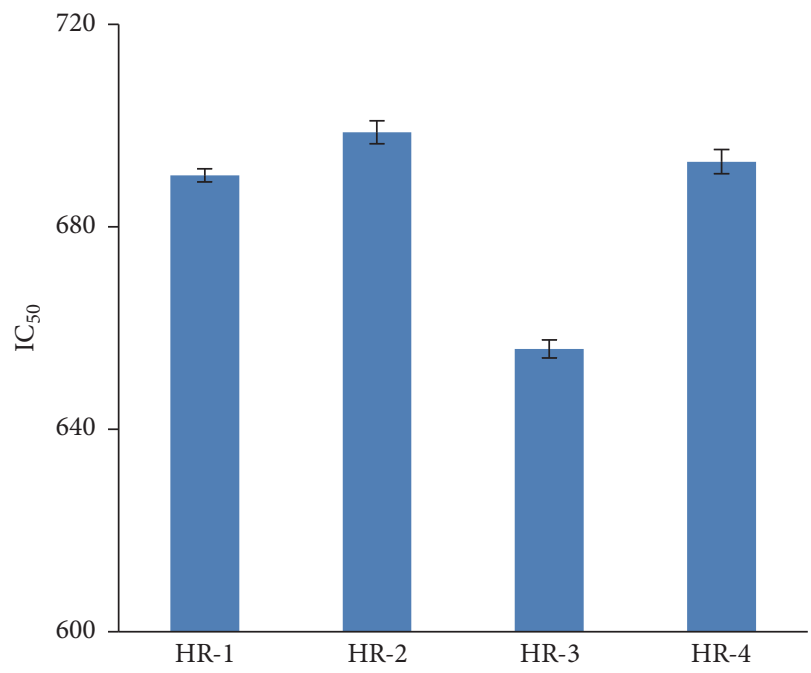

FIgure 2: Total reducing power (TRP) $\mathrm{mg} / \mathrm{mL}$ determination in different solvent extracts of $H$. rosea values is presented as mean \pm standard error from triplicate experimentation.

activity against brine shrimp larvae. The extracts resulting $\mathrm{LD}_{50}$ value was determined at different concentrations, 200, 100,50 , and $25 \mu \mathrm{g} / \mathrm{mL}$. Among all the extracts of $H$. rosea the ethyl acetate extract (HR-2) and chloroform extract (HR-3) having $\mathrm{LD}_{50}>20$ were considered significantly active and these extracts have the potential to be the candidates for the investigation of cytotoxic compounds in them (Table 2).

\subsection{Antimicrobial Activity of $H$. rosea Extracts}

3.3.1. Antifungal Activity. The antifungal potential of different solvent extracts of $H$. rosea was evaluated for the first time against three fungal strains named Aspergillus niger (FCBP0198), Aspergillus flavus (BP-0064), and Fusarium solani. The antifungal growth inhibition results are presented in Table 3.

It indicated that $n$-butanol (HR-4) showed antifungal activity with $8.73 \mathrm{~mm}$ of the zone of inhibition against $A$. flavus. Chloroform (HR-3) and $n$-hexane (HR-1) extracts showed antifungal activity with the zone of inhibition at 
TABLE 2: Median lethal dosage $\left(\mathrm{LD}_{50}\right)$ of $H$. rosea extracts against brine shrimp lethality.

\begin{tabular}{|c|c|c|c|c|c|}
\hline \multirow{2}{*}{ Plant extracts } & \multicolumn{4}{|c|}{ Percent mortality } & \multirow{2}{*}{$\begin{array}{c}\mathrm{LD}_{50} \\
(\mu \mathrm{g} / \mathrm{mL})\end{array}$} \\
\hline & $200(\mu \mathrm{g} / \mathrm{mL})$ & $100(\mu \mathrm{g} / \mathrm{mL})$ & $50(\mu \mathrm{g} / \mathrm{mL})$ & $25(\mu \mathrm{g} / \mathrm{mL})$ & \\
\hline$n$-Hexane (HR-1) & 100 & 100 & 100 & 100 & $<25$ \\
\hline Ethyl acetate (HR-2) & 20 & 10 & 10 & 0 & $>200$ \\
\hline Chloroform (HR-3) & 50 & 10 & 10 & 0 & 200.4 \\
\hline$n$-Butanol (HR-4) & 100 & 100 & 100 & 100 & $<25$ \\
\hline
\end{tabular}

TABLE 3: Antifungal activity of different solvent extracts of $H$. rosea.

\begin{tabular}{lccc}
\hline Plant extracts & \multicolumn{3}{c}{ Zone of inhibition (mm) } \\
& $\begin{array}{c}\text { Aspergillus } \\
\text { niger }\end{array}$ & $\begin{array}{c}\text { Aspergillus } \\
\text { flavus }\end{array}$ & $\begin{array}{c}\text { Fusarium } \\
\text { solani }\end{array}$ \\
\hline$n$-Hexane (HR-1) & - & $8.57^{*}$ & $6.75^{*}$ \\
Ethyl acetate (HR-2) & $11.82^{*}$ & $11.75^{*}$ & $7.68^{*}$ \\
Chloroform (HR-3) & - & $9.70^{*}$ & $8.22^{*}$ \\
$n$-Butanol (HR-4) & - & $8.73^{*}$ & - \\
\hline
\end{tabular}

Note. $*$ indicates significant results $(P<0.05)(-$ means not active). All the extracts exhibited significantly $(P<0.05)$ lower antifungal activity than that of standard, clotrimazole. However, ethyl acetate extract of $H$. rosea showed the highest antifungal activity among all extracts.

$9.70 \mathrm{~mm}$ and $8.57 \mathrm{~mm}$, respectively, against $A$. flavus and $8.22 \mathrm{~mm}$ and $6.75 \mathrm{~mm}$ against $F$. solani, while $n$-butanol extracts remain inactive against both fungal strains. Ethyl acetate (HR-2) showed significant antifungal activity against $A$. niger fungal strain and $A$. flavus with the zone of inhibition of 11.82 and $11.75 \mathrm{~mm}$. These most significant extracts would lead to the isolation of active constituents.

3.3.2. Antibacterial Activity. Antibacterial activity of $H$. rosea extracts was performed on two bacterial strains named Pseudomonas aeruginosa and Staphylococcus aureus (ATCC-6538). The data obtained exhibited that ethyl acetate (HR-2) showed significant antibacterial activity against both bacterial strains with percentage inhibition at $21.74 \mu \mathrm{g} / \mathrm{mL}$ and $40.58 \mu \mathrm{g} / \mathrm{mL}$, respectively.

However chloroform fraction (HR-3) showed minimum inhibition concentration (MIC) at $100 \mu \mathrm{g} / \mathrm{mL}$ and percentage inhibition 47.21 against $P$. aeruginosa bacterial strain, whereas $n$-butanol (HR-4) extract showed remarkable activity on $S$. aureus bacterial strain with percentage inhibition $44.72 \mu \mathrm{g} / \mathrm{mL}$. Chloroform and $n$-butanol extracts exhibited significantly $(P<0.05)$ higher antibacterial activity as compared to standard drug cefixime (Table 4 ).

\subsection{Enzymatic Activities of Hartmannia rosea Extracts}

3.4.1. Alpha-Amylase Assay. Type II diabetes can be managed by inhibiting hydrolyses of the carbohydrates and retaining the rate of D-glucose absorption into blood. Mean $\mathrm{IC}_{50}$ values of the $\alpha$-amylase investigated for extracts of $H$. rosea did not show any significance, that is, $\mathrm{IC}_{50}>200 \mu \mathrm{g} / \mathrm{mL}$, so none of the sample fractions was active, since $\alpha$-amylase inhibition for standard acarbose is $250 \mu \mathrm{g} / \mathrm{mL}$ with percentage inhibition $65.56 \%$ (Table 5). $\alpha$-Amylase inhibitors as lead molecules
TABle 4: Antibacterial activity of different solvent extracts of $H$. rosea.

\begin{tabular}{lcccc}
\hline $\begin{array}{l}\text { Plant } \\
\text { extracts }\end{array}$ & $\begin{array}{c}\text { Pseudomonas aeruginosa } \\
\text { Percentage } \\
\text { inhibition at } \\
100 \mu \mathrm{g} / \mathrm{mL}\end{array}$ & MIC & $\begin{array}{c}\text { Staphylococcus aureus } \\
\text { Percentage } \\
\text { inhibition at } \\
100 \mu \mathrm{g} / \mathrm{mL}\end{array}$ & MIC \\
\hline $\begin{array}{l}n \text {-Hexane } \\
\text { (HR-1) }\end{array}$ & 9.63 & $>100$ & $8.67^{*}$ & $>100$ \\
$\begin{array}{l}\text { Ethyl } \\
\text { acetate }\end{array}$ & 10.68 & $>100$ & 21.74 & $>100$ \\
$\begin{array}{l}\text { (HR-2) } \\
\text { Chloroform } \\
\text { (HR-3) }\end{array}$ & 47.21 & 100.0 & $39.67^{*}$ & $>100$ \\
$\begin{array}{l}n-\text {-Butanol } \\
\text { (HR-4) }\end{array}$ & 17.68 & $>100$ & $44.72^{*}$ & $>100$ \\
\hline
\end{tabular}

Note. $*$ indicates significant results $(P<0.05)$. Chloroform and $n$-butanol extracts exhibited significantly $(P<0.05)$ higher antibacterial activity than that of standard, cefixime. In addition, $n$-butanol fraction $H$. rosea extract showed the highest antibacterial activity among all extracts.

TABLE 5: Alpha-amylase inhibition activity of different solvent extracts of $H$. rosea.

$\alpha$-Amylase inhibition (\%) at $200 \mu \mathrm{g} / \mathrm{mL}$

\begin{tabular}{lc} 
Plant extracts & $\mathrm{IC}_{50}(\mu \mathrm{g} / \mathrm{mL})$ \\
\hline$n$-Hexane (HR-1) & $>200$ \\
Ethyl acetate (HR-2) & $>200$ \\
Chloroform (HR-3) & $>200$ \\
$n$-Butanol (HR-4) & $>200$ \\
\hline
\end{tabular}

in the extract may have different mode of inhibitory action and may be more suitable for the treatment of diabetes.

3.4.2. Protein Kinase Inhibition Assay. The mechanism involved in the protein kinase activity is the transfer of phosphate group from ATP molecule and attached covalently to the serine, threonine, or tyrosine residues of specific protein and produces ADP as a byproduct. Protein kinase activity test was performed on different extracts of $H$. rosea for the first time. Only the chloroform extract (HR-3) gave remarkable clear zone of inhibition $22 \mathrm{~mm}$ at $100 \mu \mathrm{g} / \mathrm{disc}$, and $11 \mathrm{~mm}$ bald phenotype was formed around HR-3 extract as compared to other tested extracts. It might block a kinase receptor from binding to ATP, preventing the phosphorylation that would benefit the cancerous cell and promote cell division. The results are presented in Table 6. 
TABLE 6: Protein kinase inhibition of different solvent extracts of $H$. rosea.

\begin{tabular}{lc}
\hline \multicolumn{2}{c}{ Protein kinase inhibition activity } \\
Plant extracts & Zone of inhibition in mm at $100 \mu \mathrm{g} /$ disc \\
\hline$n$-Hexane (HR-1) & - \\
Ethyl acetate (HR-2) & - \\
Chloroform (HR-3) & $22.0^{*}$ \\
$n$-Butanol (HR-4) & - \\
\hline
\end{tabular}

Note. $*$ indicates significant results $(P<0.05)$. The chloroform extract exhibited significantly $(P<0.05)$ higher protein kinase activity compared to surfactin standard.

The nontoxic effect of negative control (DMSO) was proved on account of lacking in inhibition zone growth. The positive control surfactin established a pronounced bald growth inhibition zone.

\section{Discussion}

There has always been search for the new constituents from herbs due to several limitations of modern drugs, since plant extracts contain tremendously active small biomolecules with selective activities in natural proportion that can contribute and exhibit acute effects in various conditions such as an oxidative stress, inflammation, and diabetes through different mechanisms.

The multiple solvent extracts of $H$. rosea were evaluated for their antioxidant potential by using DPPH as a free radical source upon reduction by accepting the hydrogen radical or electron from the sample donor antioxidant and decolorizing methanolic solution of DPPH to a yellow colored solution. All the extracts exhibited significant $(P<$ $0.05) \mathrm{DPPH}$ scavenging activity, in particular ethyl acetate extract (Table 1). These results indicated that polyphenols and flavonoid constituents are major contributors of the extracts, so their pharmacological efficacies could be attributed to the presence of such valuable principle molecules including quercetin $3-\mathrm{O}-\beta$-dallopyranoside- $3^{\prime \prime}, 6^{\prime \prime}$-diacetate (1) and two known compounds, ursolic acid (2) and gallic acid [26].

Total antioxidant capacity (TAC) of ethyl acetate (HR2 ) and $n$-butanol extracts (HR-4) showed more significant results at the ascorbic acid equivalent $\mu \mathrm{g} / \mathrm{mg}$ sample (Table 2 ). Total reducing power (TRP), in the extracts of $H$. rosea, has been reported for the first time. The reducing power is normally associated with the reductones that have been correlated with antioxidant capability of plant extracts [26, 27] (Figure 2).

The antioxidant activity also revealed that moderately best polar solvent extraction would be recommended for the isolation of constituents with cytotoxicity to be used as anticancer and antiobesity in adipogenesis [26] (Table 2).

Microscopic organisms responsible for fungal infections are capable of attacking the epithelial tissues so antifungal agents are used to inhibit the fungi growth or to kill the fungi. These agents act against fungal infection by three different modes, that is, inhibition of cell division, inhibition of cell wall formation, and cell membrane disruption. The antifungal potential of different solvent extracts of $H$. rosea was evaluated for the first time against three fungal strains named Aspergillus niger (FCBP-0198), Aspergillus flavus (BP-0064), and Fusarium solani. The antifungal growth inhibition results are presented in Table 3. Antibacterial agents are used to treat the infections caused by bacteria. They have the ability to fight against bacterial cells instead of animal cells because of the difference in the biosynthetic processes and structure of the bacterial and animal cells. The antibacterial agents act against bacterial cells through three different mechanisms. The first method is the inhibition of cell metabolism of microorganism by resisting an enzyme catalyzed reaction that occurs only in bacterial cell and not in animal cell. Second method is the inhibition of bacterial cell wall that ultimately results in the cell death and cell lyses. Third method includes the interaction of antibacterial agents with the plasma membrane of bacterial cells that affects the permeability of membrane. Conclusively, $n$-butanol extracts of $H$. rosea have the most significant antibacterial activity among all extracts (Table 4).

$\alpha$-Amylase is a protein enzyme present in human secretions, fungi, and seeds containing starch [28]. It is responsible for the hydrolyses of polysaccharides such as carbohydrates, glycogen, and starch, which result in the formation of maltose, dextrin, glucose, and glucoamylase. It serves as the major digestive enzyme and helps in intestinal absorption [29]. Since $\alpha$-amylase is responsible for the breakdown of carbohydrates long chain, diabetes mellitus disease characterized by hyperglycemia can be controlled through inhibition of $\alpha$-amylase. Particularly, type II diabetes can be managed by inhibiting hydrolyses of the carbohydrates and retaining the rate of D-glucose absorption into blood. Since $\alpha$-amylase inhibition for standard acarbose is $250 \mu \mathrm{g} / \mathrm{mL}$ with percentage inhibition $65.56 \%, \alpha$-amylase inhibitors as lead molecules in the extract may have different mode of inhibitory action and may be more suitable for the treatment of diabetes.

As the protein kinase targeted therapeutics in cancer is promising, though it is not specified and may not be used in the treatment, however, such mioties are required to comprehend physiological roles of protein kinase [30]. The mechanism involved in the protein kinase activity is the transfer of phosphate group from ATP molecule attached covalently to the serine, threonine, or tyrosine residues of specific protein and produces ADP as a byproduct $[31,32]$. To comprehend the efficacy of the HR extracts as anticancer agent, protein kinase activity test was performed on different extracts of $H$. rosea for the first time. Protein kinase activity is a promising anticancer feature in drug designing; thus HR3 extract will be further studied for the isolation of active constituents and studying their mechanism of action.

\section{Conclusion}

Hartmannia rosea has a tradition of worldwide potential use as medicinal plant. It is concluded from the present studies that ethyl acetate, chloroform, and $n$-butanol extracts of this plant are biologically most effective. Therefore they will be the prospecting study targets for the discovery of lead principle constituents and their pharmaceutical potential and drug designing. 


\section{Conflicts of Interest}

The authors declare no conflicts of interest.

\section{Acknowledgments}

This study was supported by National Research Program for Universities by Higher Education Commission, Pakistan (Project no. 02100), New Century Excellent Talents of China (NECT-13-0695), and National Nature Science Foundation of China (81102623).

\section{References}

[1] G. Brusotti, I. Cesari, A. Dentamaro, G. Caccialanza, and G. Massolini, "Isolation and characterization of bioactive compounds from plant resources: the role of analysis in the ethnopharmacological approach," Journal of Pharmaceutical and Biomedical Analysis, vol. 87, pp. 218-228, 2014.

[2] C. H. Hoch and H. P. Raven, "Flora of Pakistan," Pakistan Plant Database, vol. 139, 41 pages, 1981.

[3] V. Srivastava, M. P. Darokar, A. Fatima et al., "Synthesis of diverse analogues of Oenostacin and their antibacterial activities," Bioorganic \& Medicinal Chemistry, vol. 15, no. 1, pp. 518525, 2007.

[4] R. A. Gibson, D. R. Lines, and M. A. Neumann, "Gamma linolenic acid (GLA) content of encapsulated evening primrose oil products," Lipids, vol. 27, no. 1, pp. 82-84, 1992.

[5] C. Avendaño and J. C. Menendez, Medicinal Chemistry of Anticancer Drugs, Elsevier, 2008.

[6] C. D. Pellegrina, G. Padovani, F. Mainente et al., "Anti-tumour potential of a gallic acid-containing phenolic fraction from Oenothera biennis," Cancer Letters, vol. 226, no. 1, pp. 17-25, 2005.

[7] D. J. Newman and G. M. Cragg, "Natural products as sources of new drugs over the 30 years from 1981 to 2010," Journal of Natural Products, vol. 75, no. 3, pp. 311-335, 2012.

[8] Y. K. Márquez-Flores, H. Montellano-Rosales, M. E. C. Aldrete, and M. E. Meléndez-Camargo, "Anti-inflammatory activity of aqueous and methanolic extracts of Oenothera rosea L' Hér. ex Ait in the rat," Revista Mexicana de Ciencias Farmaceuticas, vol. 40, no. 3, pp. 11-16, 2009.

[9] S. Vargas, S. Zavala, A. Miguel, G. Pérez, and M. Rosa, "Preliminary study of antidiarrhoeic activity in five Mexican plant species," Phytotherapy Research, vol. 12, no. S1, pp. S47-S48, 1998.

[10] P. Lorenz and F. R. Stermitz, "Oxindole-3-acetic acid methylester from the flowers (buds) of Oenothera species," Biochemical Systematics and Ecology, vol. 28, no. 2, pp. 189-191, 2000.

[11] V. Tene, O. Malagón, P. V. Finzi, G. Vidari, C. Armijos, and T. Zaragoza, "An ethnobotanical survey of medicinal plants used in Loja and Zamora-Chinchipe, Ecuador," Journal of Ethnopharmacology, vol. 111, no. 1, pp. 63-81, 2007.

[12] M. Meckes, R. A. David, V. Nava-Aguilar, and A. Jimenez, "Activity of some Mexican medicinal plant extracts on carrageenan-induced rat paw edema," Phytomedicine, vol. 11, no. 5, pp. 446-451, 2004.

[13] L. Niklová, S. Schmidt, K. Habalová, and S. Sekretár, "Effect of evening primrose extracts on oxidative stability of sunflower and rapeseed oils," European Journal of Lipid Science and Technology, vol. 103, no. 5, pp. 299-306, 2001.
[14] T. MacDonald, J. Spencer, S. Murch et al., "Immunoepidemiology of intestinal helminthic infections. 3. Mucosal macrophages and cytokine production in the colon of children with Trichuris trichiura dysentery," Transactions of the Royal Society of Tropical Medicine and Hygiene, vol. 88, no. 3, pp. 265-268, 1994.

[15] S. Pérez-Gutiérrez, R. Vargas-Solís, and S. Zavala, "Inhibitory effect of five plant extracts on heart rates of rats," Phytotherapy Research, vol. 12, no. S1, pp. S49-S50, 1998.

[16] R. Ullah, I. Hussain, and S. Ahmad, "Phytochemical and biological evaluation of phlomis bracteosa: a review," Life Science Journal, no. 10, p. 7, 2013.

[17] H. Fatima, K. Khan, M. Zia, T. Ur-Rehman, B. Mirza, and I.-U. Haq, "Extraction optimization of medicinally important metabolites from Datura innoxia Mill.: an in vitro biological and phytochemical investigation," BMC Complementary and Alternative Medicine, vol. 15, article 376, 2015.

[18] G. Clarke, K. Ting, C. Wiart, and J. Fry, "High correlation of 2,2diphenyl-1-picrylhydrazyl (DPPH) radical scavenging, ferric reducing activity potential and total phenolics content indicates redundancy in use of all three assays to screen for antioxidant activity of extracts of plants from the malaysian rainforest," Antioxidants, vol. 2, no. 1, pp. 1-10, 2013.

[19] K. Pyrzynska and A. Pękal, "Application of free radical diphenylpicrylhydrazyl (DPPH) to estimate the antioxidant capacity of food samples," Analytical Methods, vol. 5, no. 17, pp. 4288-4295, 2013.

[20] B. Sandeep, P. Chandrakant, and S. Magdum, "Brine shrimp lethality activity of euphorbia hirta linn," International Journal of Pharmacy and Pharmaceutical Sciences, vol. 4, 2012.

[21] M. Islam, S. Shahriar, M. Jesmin, M. Ali, and J. Khanam, "Antibacterial activities of some transition metal schiff base complexes," International Letters of Chemistry, Physics and Astronomy, vol. 10, pp. 12-20, 2013.

[22] G. Yao, F. M. Sebisubi, L. Y. C. Voo, C. C. Ho, G. T. Tan, and L. C. Chang, "Citrinin derivatives from the soil filamentous fungus Penicillium sp. H9318," Journal of the Brazilian Chemical Society, vol. 22, no. 6, pp. 1125-1129, 2011.

[23] R. Chakrabarti, B. Singh, V. N. Prakrith, L. Vanchhawng, and K. Thirumurugan, "Screening of nine herbal plants for in vitro $\alpha$-amylase inhibition," Asian Journal of Pharmaceutical and Clinical Research, vol. 7, no. 4, pp. 84-89, 2014.

[24] E.-S. S. Abdel-Hameed, "Total phenolic contents and free radical scavenging activity of certain Egyptian Ficus species leaf samples," Food Chemistry, vol. 114, no. 4, pp. 1271-1277, 2009.

[25] S. Chanda and R. Dave, "In vitro models for antioxidant activity evaluation and some medicinal plants possessing antioxidant properties: an overview," African Journal of Microbiology Research, vol. 3, no. 13, pp. 981-996, 2009.

[26] R. Rashid, R. Hameed, M. I. Choudhary, F. Mukhtar, and A. K. Khan, "Anti-adipogenic and cytotoxic effects of a new compound from Hartmannia rosea G. Don," Current Pharmaceutical Analysis, vol. 11, no. 4, pp. 300-307, 2015.

[27] R. Subramanian, A. Asmawi, Z. Sadikun, and A., "In vitro alpha-glucosidase and alpha-amylase enzyme inhibitory effects of Andrographis paniculata extract and andrographolide," Acta Biochimica Polonica, vol. 50, no. 2, pp. 391-398, 2008.

[28] Z. Xiao, R. Storms, and A. Tsang, "A quantitative starch-iodine method for measuring alpha-amylase and glucoamylase activities," Analytical Biochemistry, vol. 351, pp. 146-148, 2006.

[29] S. S. Nair, V. Kavrekar, and A. Mishra, "In vitro studies on alpha amylase and alpha glucosidase inhibitory activities of selected 
plant extracts," European Journal of Experimental Biology, vol. 3, no. 1, pp. 128-132, 2013.

[30] G. Giamas, J. Stebbing, C. E. Vorgias, and U. Knippschild, "Protein kinases as targets for cancer treatment," Pharmacogenomics, vol. 8, no. 8, pp. 1005-1016, 2007.

[31] M. Curtin, "Choosing the best kinase assay to meet your research needs," Cell Notes, vol. 13, pp. 11-15, 2005.

[32] W. Barbara, G. Saxena, Y. Wanggui, D. Kau, S. Wrigley, and R. Stokes, "Identifying protein kinase inhibitors using an assay based on inhibition of aerial hyphae formation in Streptomyces," The Journal of Antibiotics, vol. 55, no. 4, pp. 407-416, 2002. 

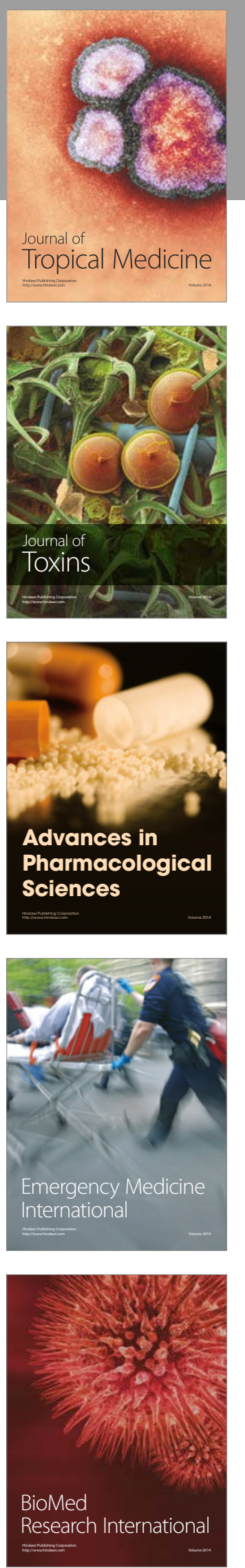
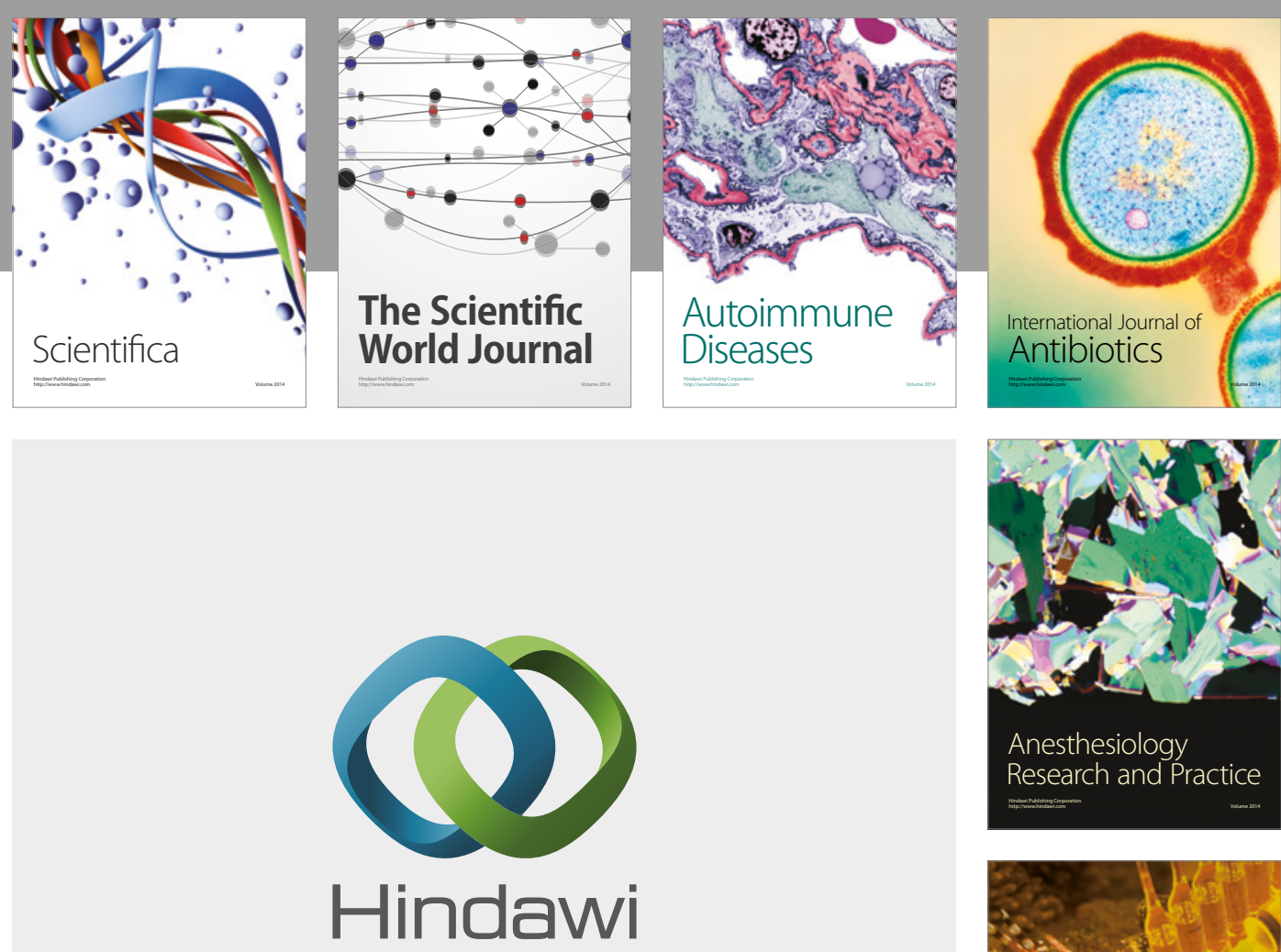

Submit your manuscripts at

https://www.hindawi.com
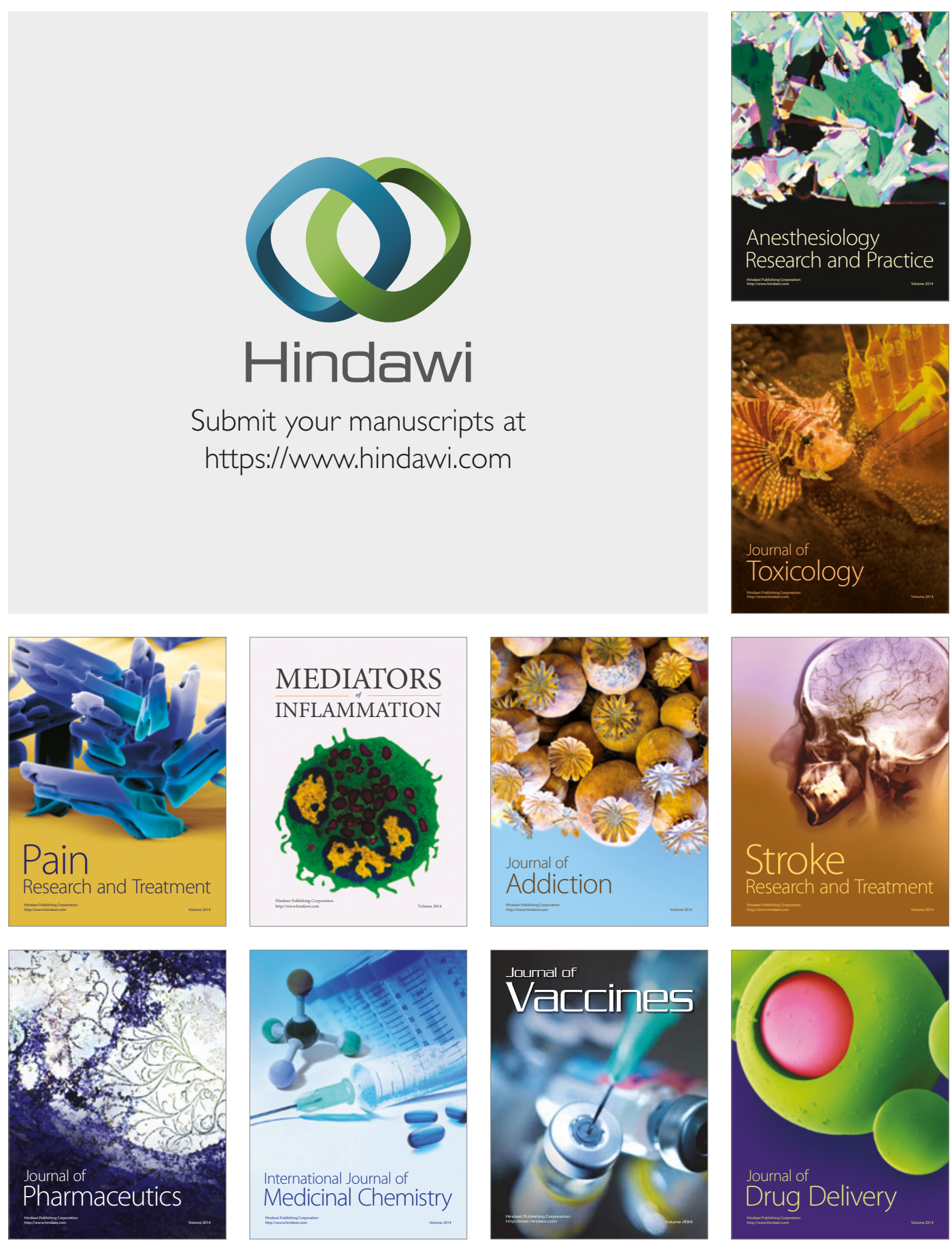